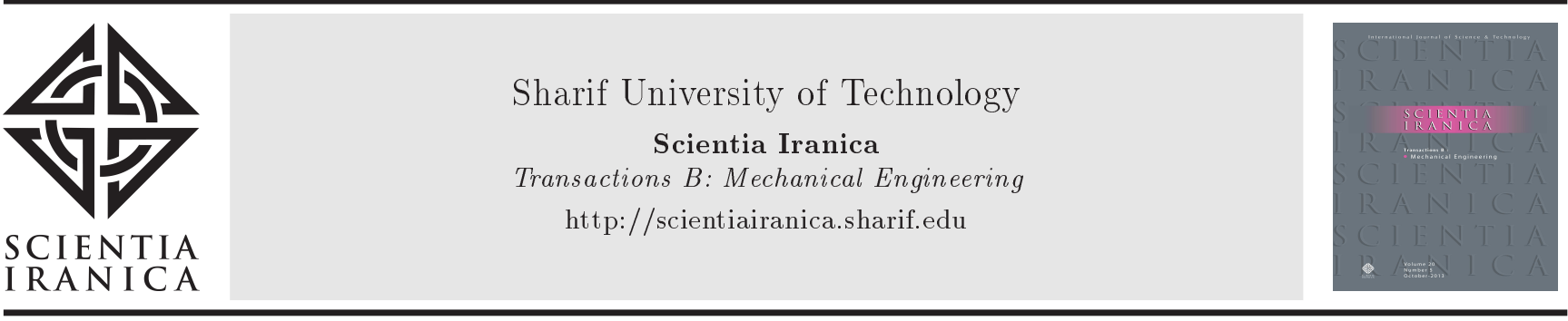

\title{
Comparison of hydrodynamic performance of a monohull planing vessel equipped by combined transverse step and transom wedge with a no appendage model: An experimental study
}

\author{
S.M. Sajedi, P. Ghadimi*, M. Sheikholeslami, and M.A. Ghassemi \\ Department of Marine Technology, Amirkabir University of Technology, Tehran, Iran.
}

Received 5 July 2020; received in revised form 14 August 2020; accepted 9 November 2020

\author{
KEYWORDS \\ High speed planing \\ craft; \\ Experimental study; \\ Transverse step; \\ Wedge; \\ Porpoising.
}

\begin{abstract}
One of the most well-known strategies to eliminate or reduce the longitudinal instabilities in planing hull, is to reduce the trim of the craft. In the current study, porpoising was controlled through creating a transverse step, and by adding a wedge to the stern and transverse step of the vessel. Usually, the performance of stepped boats is not suitable in the pre-planing regime. However, through the proposed method, stepped model performance can be improved prior to the planing regime. The investigated craft was a $2.56 \mathrm{~m}$ long monohull high speed model with a speed range of $1,3,5,7$ and $9 \mathrm{~m} / \mathrm{s}$. The obtained results indicated that the best performance was acquired by the step and wedge model at the beginning of the planing regime. From 3 to $7 \mathrm{~m} / \mathrm{s}$, the drag of stepped and wedged models had the lowest value and above $7 \mathrm{~m} / \mathrm{s}$ and at $9 \mathrm{~m} / \mathrm{s}$, the stepped model had the lowest resistance. By combining the step and wedge models, the largest reduction of the rim angel was occurred (at speeds of 3 to $9 \mathrm{~m} / \mathrm{s}$ ). Thus, through combining the step and wedge models the poor performance of the stepped models could be improved prior to the planing regime.

(C) 2021 Sharif University of Technology. All rights reserved.
\end{abstract}

\section{Introduction}

Most of the researches conducted on the performance improvement of planing hulls have focused on the following issues: to minimize the motion and acceleration exerted on the bow and center of gravity of the vessel (seakeeping condition) and to achieve a minimum resistance for the vessel at different speeds and in different conditions. As far as seakeeping performance is concerned, different motions of the vessel such as heave, pitch, and roll have been investigated in various

\footnotetext{
*. Corresponding author. Tel.: +982164543110;

Fax: +982166412495

E-mail address: pghadimi@aut.ac.ir (P. Ghadimi)
}

studies. Martin [1] developed an analytical method for predicting the motion of planing hulls in waves. Zarnick [2,3] introduced analytical procedures for estimating the motion and accelerations of a planing hull in the presence of regular or irregular waves. Moreover, Ghadimi et al. [4-6] developed mathematical models to study the roll, pitch, and heave motions of the planing hulls. The results of these studies showed that there are always limitations to achieve the minimum motion and to minimize the acceleration exerted on the vessel bow and center of gravity for the vessel at different speeds and in different weather conditions. To achieve this goal, some researchers proposed various solutions over the past years.

\subsection{Stepped hulls}

Providing step(s) in the planing hull is one of the most 
practical solutions which have recently been investigated by some researchers. Clement and Pope [7] as the pioneers in the field performed valuable experimental studies on the stepped hulls. They conducted extensive experiments on the stepped hull and step-less crafts and presented different diagrams for comparing the performance of the studied crafts in different conditions and suggested an optimum location and height for the step. Also, Clement and Koelbel [8] studied the effects of mounting a step on the planing hulls and found a proper place for the step in the vessel. The position at which the step placement causes the vessel to reach the minimum resistance and maximum lift is considered as the proper place. From a different viewpoint, it implies a position at which the lift to drag ratio is favorable.

Clement [9] calculated and compared the resistance of non-stepped and one-stepped planing hulls. In that experiment, a model of V-shaped type and a step-less planing hull of series 62 from Davidson Lab models were used. The results of the tests of the models were 27 different combinations for a single-stepped planing hull, and the effect of important parameters such as deadrise angle, step height, the angle between the fore and aft body of the craft, and the length of the aft body were investigated. In 1999, Barry and Duffty [10] used a combined method in which the foil and step models were combined. They investigated the effect of this combined method on a high-speed craft to examine the performance of the hybrid craft. By applicating this combined method, the seakeeping condition improved and the results showed that the negative trim angle of foil could result in the reduction of the resistance. Savitsky and Morabito [11] sought to determine the rooster tail at the transom of a high-speed craft and conducted some experiments on the prismatic crafts with deadrise angles of 10,20 , and 30 degrees. They introduced different relations for determining the generated rooster tail. These relations facilitate the design of the first step. Svahn [12] followed Savitsky et al. [11] and by utilizing their formulas, achieved new definitions of the aft body through which the lift and drag of a planing hull could be calculated. However, in 2012, Garland and Maki [13] examined the effect of step height on a two-dimensional fashion and it was revealed that the step height, depending on its position, plays a greater role in determining the ratio of lift to drag of the craft. Taunton et al. [14] investigated the craft behavior in calm water and in the presence of irregular waves. The results of this study showed that the effect of a step on the accelerations of the bow and center of gravity depends on the step location. On the other hand, O'Reilly et al. [15] presented an analytical method for determining the wake of the aft body and showed that the results of the method are in good agreement with the results of the CFD method. Based on Savitisky formulations, Loni et al. [16] presented a computational program for the stepped hull, in which the effect of craft parameters such as step location and height were considered. Meanwhile, Lee et al. [17] investigated a stepped high-speed craft experimentally and numerically in calm water with ten types of steps and different centers of gravity and length. In all cases, the drag of the stepped hull was found to be less than a step-less hull. The craft with the lowest front step height and the highest aft step height showed the best performance in drag reduction. Veysi et al. [18] also studied the pressure distribution, hydrodynamic performance, and wake profile of stepped planing hull, numerically. Recently, De Marco et al. [19] performed a multi-functional experimental and numerical simulation on a single-step craft. Their study aimed to determine the dry surface of the aft body. The experimental and numerical studies conducted on the stepped hulls since 2019 are summarized as follows:

Najafi et al. [20]. They examined experimentally the effect of changes in step length and height on the Fridsma model (2019);

Najafi and Nowruzi [21]. They investigated the effect of step length and height changes on the performance of the single-step high-speed boats. They found that the length and height of the steps played an important role in reducing drag, especially at high speeds (2019);

Chooran et al. [22]. They examined numerically the effect of step height on the performance of the planing hull. They concluded that the ventilation improves with increasing step height, but it could make the vessel unstable (2019);

Kazemi et al. [23]. They formulated the profile of the wake of the transom of a vessel, numerically (2019);

Ghadimi et al. [24]. Regarding the small Froude numbers, taking into account the second step does not have a positive effect on the boat (2019);

Dashtimanesh et al. [25]. They concluded that as the height of the steps increases, the resistance decreases (2019);

Doustdar and Kazemi [26]. They examined numerically the effects of two fixed and dynamic mesh methods on a stepped vessel (2019);

Yang et al. [27]. They examined numerically the air cavity of the stepped model (2019);

Cucinotta et al. [28]. The amount of wet surface of 
the stepped model was examined, experimentally and numerically (2019);

Ghadimi and Panahi [29]. They examined numerically the effect of step on motion of Yaw (2019);

Nourghassemi et al. [30]. They examined numerically the effect of the changes in the height of steps on boat performance (2018);

Esfandiari et al. [31]. They examined two vessels without step and two steps in a regular wave and concluded that the motions and accelerations of a twostep vessel at wavelengths greater than the length of the model were less than stepless vessel (2019);

Najafi et al. [32]. Using experimental methods, they examined the effect of geometric parameters on a single-step vessel (2019);

Judgea et al. [33]. The experimental and numerical studies were conducted on a single-hulled high-speed vessel (2020);

Niazmand et al. [34]. The experimental and the $2 \mathrm{D}+\mathrm{T}$ mathematical modeling method were presented for a two-step model (2020);

Afriantoni et al. [35]. They examined numerically the stability of the stepped model (2020).

\subsection{Wedge mounted hulls}

To improve the capability and to minimize the resistance of planing hulls, some appendages such as wedges, trim tabs, and interceptors could be mounted. Accordingly, the researchers who investigated the planing hulls, focused on the effect of these appendages. Savitsky and Brown [36] provided some empirical relations to calculate the lift, moment and resistance resulting from mounting a wedge on a planing hull in a steady state condition. Grigoropoulos and Loukakis [37] studied the effect of different mounted wedges on the performance of planing hulls. Katayama [38] conducted comprehensive research on the causes of porpoising phenomenon in the vessels based on the motion equations. In the same vein, Ikeda and Katayama [39] published the result of another study on porpoising. Morabito [40] investigated the effect of shallow water on the proposing. On the other hand, Millard [41] reported that in some special conditions, mounting a wedge on a planing hull could lead to the elimination of the proposing phenomenon. Some researchers such as Steen et al. [42] investigated the effect of the appendages on the stability of the planing hulls. Mansouri and Fernandes [43] studied the effects of an interceptor on the performance of planing hulls in two dimensions through a numerical approach. They subsequently extended their studies to a three-dimensional case [44]. On the other hand, through experimental works, following the installation of these lifting surfaces the behavior of the boat could be predicted. This topic was the subject of some important researches. Tsai et al. [45] studied the effects of an interceptor on the performance of planing hulls. Other findings regarding the effects of the interceptors on the performance of planing hulls have been reported in different experimental studies like those conducted by Tsai and Hwang [46] and Karimi et al. [47]. To demonstrate the critical contribution of lifting surface in providing a better planing condition, and to select an appropriate condition for the lifting surface a more detailed investigation is needed. The results of such a precise study could serve as strong evidence that assure the efficiency of the lifting surface and could show its capability and significant effect in this regard [48]. The physics of turbulent fluid flow was the subject of various numerical investigations [49-51]. Ghadimi et al. [52] also performed an experimental study on the effect of the wedge on the seakeeping of planing hulls. To reduce the resistance and control the trim angle is another motivation that urged us to install the appendages such as wedge and trim tabs on the vessels. Karafiath and Fisher [53], investigated the effect of the mounted wedge on the powering performance of the destroyer and frigate size ships through numerical and experimental efforts. The results of their studies showed that the mounted wedge could reduce the resistance and trim, at high speeds. Also, Wang [54] showed that an extra hydrodynamic force, provided by the wedge and trim tab, could reduce the resistance and trim in planing hulls. Meanwhile, Jang et al. [55] investigated the effect of a wedge on the performance of a passenger ship, numerically. Ghadimi et al. [56] conducted a parametric study and proposed an algorithm for determining the resistance and running trim tab of the vessel. However, the scope of the subject is so wide that any approach such as analytical, experimental and numerical methods can be applied, but the literature review shows that the researchers have always preferred experimental studies over other methods. More details could be obtained through numerical methods, however, due to the complexity and fully nonlinear nature of the flow surrounding the planing hulls, taking any superficial approach would result in the reduction of the precision of the results. This, in turn, could be associated with a costly reliable simulation in terms of the computational contribution. Given the easily applied nature of the analytical method, the latter received special attention from researchers, and many investigations were conducted on the prediction of the different aspects of the performance of the planing hulls, using this method. However, the absence of 
a comprehensive analysis covering all aspects of the planing hulls is very evident. The fail of the fulfillment of this objective follows from the same reason as for the numerical method [57-63]. The experimental and numerical studies conducted on the lifting surfaces, since 2019, can be summarized as follows:

Mancini et al. [64]. They improved the performance of the boat by changing the position of the step and wedge (2019);

Jokar et al. [65]. With the help of the trim tab, they controlled the instability of a boat (2020);

Song et al. [66]. The effect of the stern flap on the performance and thrust system of a vessel in a semidisplacement boat was investigated (2019);

Wang et al. [67]. The effect of the stern flap on a catamaran in the wave was examined (2020);

Hou et al. [68]. With the help of foil in the stern, they were able to optimize fuel consumption in a semidisplacement vessel (2020);

Deng et al. [69]. They examined the effect of interceptor on the stern flow pattern (2020);

Zou et al. [70]. They examined the performance of a two-step model with a flap in the stern of the boat experimentally and numerically. As the flap angle increases, the resistance in the planing regime increases (2019);

Ghadimi et al. [71]. The effect of the wedge on the mono-hull vessel in calm water was investigated experimentally (2019).

As it is clear from the literature, several methods are proposed for reducing and/or eliminating the porpoising phenomenon in high speed planing hulls. This is usually accomplished by altering the hull bottom and/or transom. All of these methods could lead to the reduction of porpoising, but change in the hull bottom or transom could affect the pressure distribution, which in turn could undesirably reduce or increase another parameter in the vessel. Therefore, the evaluation of the effect of added elements or appendage on parameters like drag, trim, and rise up is necessary. On the other hand, a comparison between these methods can be determinant in selecting an optimal method that has not been presented, so far. In the present study, two methods are proposed for reducing or eliminating the porpoising phenomenon in planing hulls; providing a transverse step in the vessel and using a combined method in which a wedge is added to the stern and a transverse step in the vessel is considered. In the present study, three models including the noappendage, single-step, and wedged and stepped model are compared. Meanwhile, regarding the high-speed vessels, one of the most important issues is to reach the planing regime as quickly as possible, the topic which constitutes the main subject of the present study. Ghadimi et al. [52] have previously examined the model of no-appendage. The single step model as well as wedged and stepped model are examined in the present study. The method used in the present study is the result of the combination of the wedge and transverse step models. This combined method was used to eliminate the porpoising phenomenon and to improve the performance of the stepped model prior to the planing regime. The originality of the present study follows from employing this combined method to fulfill the above-mentioned objectives. The high resistance in the pre-planing regime is one of the weaknesses of the stepped model. This paper also presents a comprehensive comparison between four methods and their effects on the different parameters including drag, trim, and rise-up via experimental tests. These tests are performed in calm water at different speeds of 1,3 , 5,7 and $9 \mathrm{~m} / \mathrm{s}$.

\section{Problem definition}

Motion regimes in planing hulls are characterized by the longitudinal Froude number. This non-dimensional number is represented by:

$$
F n_{L}=\sqrt{\frac{V}{g L}},
$$

where " $V$ " and " $g$ " are the speed and gravity acceleration $\left(\mathrm{m} / \mathrm{s}^{2}\right)$ of the vessel and $L$ is the length of the water line in the static state. Froude numbers less than 0.5 correspond to the displacement regime, while Froude numbers in the range $0.5-1$ corresponds to semi-planing regime, and higher Froude numbers correspond to the planing regime. The porpoising phenomenon occurs in the planing regime for a high-speed planing craft in the form of a longitudinal instability. The imbalance between weight force and hydrodynamic force in the vessel transom is one of the main causes of proposing. As the centers of these two forces move away from each other, the probability of the occurrence of porpoising increases. In general, two methods are recommended for moving the center of gravity away from the center of hydrodynamic force. When the center of gravity cannot be changed longitudinally, the center of the hydrodynamic force should be displaced by adding an element to the transom or by changing the shape of the bottom. For example, two methods are proposed in Figure 1 for changing the center of hydrodynamic 


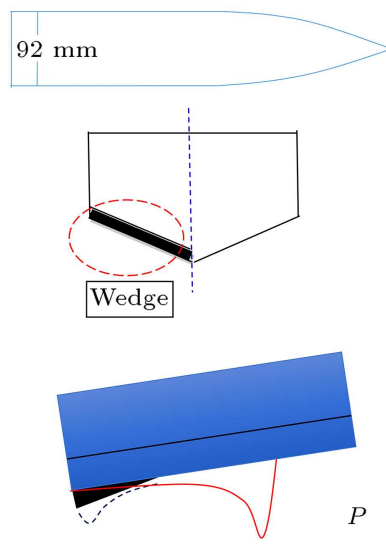

(a)
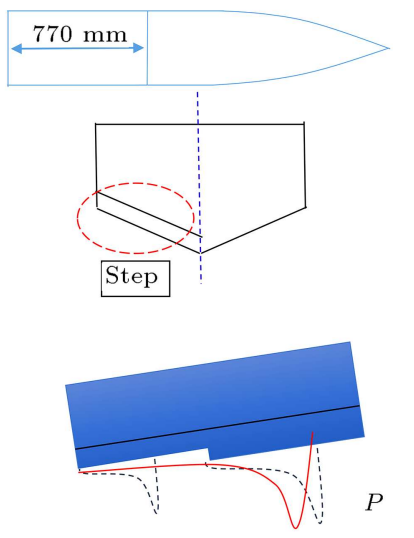

(b)
Figure 1. Shapes and effects of (a) wedge and (b) step on the dynamic pressure acting on the floor of a planing mono-hull: dynamic pressure without appendages (solid line) and dynamic pressure due to the application of a wedge or step (dashed line).

shows the pressure distribution on the centerline of the vessel bottom. It is quite obvious that the addition of the wedge causes an increase in the lift force exerted on the bottom of the vessel near the transom. The effect of the addition of the step on the centerline pressure force is illustrated in Figure 1(b). As evident in this figure, by providing two pressure peaks, the added step shifts the concentration of hydrodynamic pressure toward the transom. Changes in hydrodynamic forces could increase or decrease the drag, lift, and trim of the vessel. One way to increase the stability of a high-speed craft is to use a transverse step. However, other elements such as a wedge can also be used to eliminate the porpoising by increasing the pressure at the stern location. Therefore, using step(s) and wedge(s) together in a vessel is an interesting strategy that can be considered as an innovative solution to reduce the porpoising.

One of the weaknesses of the stepped boats relates to the regime prior to planing. Clement and Pope [7] have performed the tests on two models. One of these models was a stepped model and the other was a nonstep model. The resistance of the stepped model prior to the planing regime is greater than that of the model with no step. Another aim of this study is to use a combination of step and wedge models to reduce the resistance of the step.

\subsection{Physical description of the models}

The wedged model and the model without any appendage have been previously tested by Ghadimi et al. [52]. However, the single-step model and combined wedged and stepped model are examined in the present study. One of the models investigated in this research was a composite mono-hull planing craft made of fiberglass. This model which is a 1:5 scaled down V-

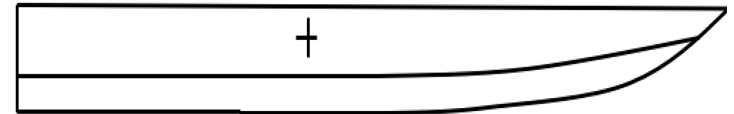

(a)

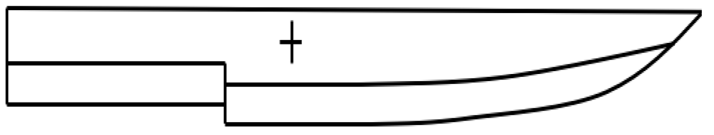

(b)

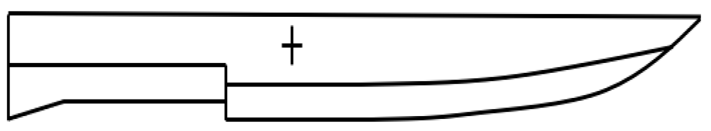

(c)

Figure 2. The tested models: (a) Model A without a wedge and step, (b) Model B with step, and (c) Model C with a wedge and step.

Table 1. Principal characteristic of the investigated model.

\begin{tabular}{cc}
\hline Parameter & Value \\
\hline$L$ & $2640 \mathrm{~mm}$ \\
LCG & $790 \mathrm{~mm}$ of transom \\
VCG & $185 \mathrm{~mm}$ \\
LBP & $2360 \mathrm{~mm}$ \\
$M$ & $86 \mathrm{~kg}$ \\
$\tau_{S}$ & $2.34 \mathrm{deg}$ \\
$B$ & $551 \mathrm{~mm}$ \\
\hline
\end{tabular}

shaped mono-hull craft had a length-to-width ratio of 4.78. The deadrise angle of the models was fixed at 24 degrees. The weight of no-wedge and transverse steps model (shown in Figure 2) was $86 \mathrm{~kg}$ and its Longitudinal Center of Gravity (LCG) was located at $0.791 \mathrm{~m}$ from the transom stern. The principal characteristics of the model are displayed in Table 1.

Other models were generally similar to the model with no appendage (Model A) and were slightly different from it. Model A has been previously tested by Ghadimi et al. [52]. Model B has a transverse step at a distance $770 \mathrm{~mm}$ from the stern with a height of $25 \mathrm{~mm}$. Model $\mathrm{C}$ was a combination of wedge and step models, implying that it had both step and wedge. The sheer plan of all models is shown in Figure 2.

The body plan view of Model A is displayed in Figure 3.

Based on the experimental studies carried out in recent years [72], the height of a wedge is less than half of the height of the boundary layer. Given that the height of the boundary layer at the aft of the vessel was about $1 \mathrm{~cm}$, the height of the wedge was considered to be $5 \mathrm{~mm}$. As revealed through experimental researches [72], if the height increases, the trim of the vessel will reduce and its resistance will 


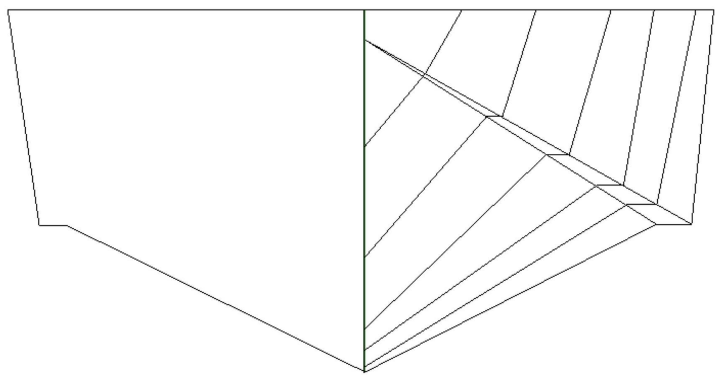

Figure 3. Body plan for Model A.

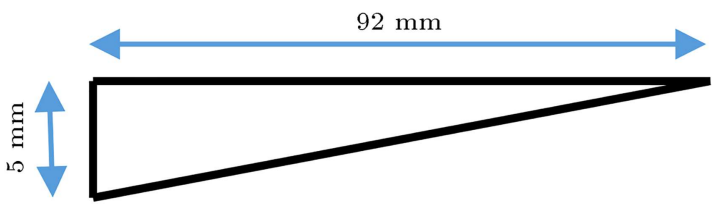

Figure 4. Wedge dimensions (schematic of the mounted wedge).

increase. A schematic of the wedge which is mounted on the aft section of the vessel is presented in Figure 4.

The selected length and height of the step were in fine agreement with the findings of previous studies (Table 2). Table 2 shows the characteristics of the single-step models tested in different towing tanks [73$75]$.

As is evident from Table 2, the height of the steps equals $5 \%$ of the beam of the model and the length of the first step approximately equals $30 \%$ of the length of the model of the transom.

\subsection{Experimental setup}

The towing tests for planing hulls have been previously performed in various researches [76-81] and in the present study, the efforts have been made to follow the recommendation provided by the previous studies. Meanwhile, the International Towing Tank Conference (ITTC) [82] recommendations for high speed crafts are implemented in all the considered tests. The experiments were carried out in the National Persian Gulf Marine Laboratory, and the main characteristics of the towing tank are displayed in Table 3 . As illustrated in the table, there are three indicators to determine the trim and total resistance. The drag was determined at the location of the intersection of the shaft line and LCG. To provide an inclusive and balanced view, four high speed cameras are mounted to capture the longitudinal, back, front, and bottom images of the model. These cameras moved forward with the carriage speed.

\subsection{Experimental tests and parameter measurements}

Only two motions of heave and pitch were possible for models, due to the special mode of their installation. Therefore, no sway, yaw, and roll motions were observed. In these experiments, it was required that the centers of gravity and inertia be placed in the appropriate position. The center of the gravity of the model was $790 \mathrm{~mm}$ away from the stern and its radius of gyration was equal to $25 \%$ of the length of the model. The measured parameters used in these tests included the resistance, rise up, and trim of the model. The measurement sensors consisted of two potentiometers that measured the rise up and trim of the model and a resistance sensor that measured the net resistance of

Table 2. Previously tested models.

\begin{tabular}{cccc}
\hline Researcher & Year & $\begin{array}{c}\text { Step height } \\
\text { (percent of beam) }\end{array}$ & $\begin{array}{c}\text { Step location } \\
\text { (percent of length } \\
\text { forward of transom) }\end{array}$ \\
\hline Gassman and Kartinen [73] & 1994 & 10 & 38 \\
Becker et al. [74] & 2008 & 1.7 & 32 \\
Taunton et al. [75] & 2010 & - & 32 \\
Present model & 2020 & 5 & 30 \\
\hline
\end{tabular}

Table 3. Towing tank specifications.

\begin{tabular}{cc}
\hline Specifications & Size \\
\hline Length of the towing tank & $400 \mathrm{~m}$ \\
Width of the towing tank & $6 \mathrm{~m}$ \\
Depth of the towing tank & $4 \mathrm{~m}$ \\
Maximum speed of carrier & $18 \mathrm{~m} / \mathrm{s}$ \\
Density of towing tank water & $1002 \mathrm{~kg} / \mathrm{m}^{3}$ \\
Kinematic viscosity of towing tank water & $9.75831 \mathrm{E}-07 \mathrm{~m}^{3} / \mathrm{s}$ \\
Temperature of water & $21^{\circ} \mathrm{C}$ \\
\hline
\end{tabular}


the model. The load cell at the center of the gravity was located at an angle of 24 degrees from the horizon in such a way that the towing was carried out in the center of gravity along the shaft line.

\section{Results and discussion}

For each of the four considered models, the empirical tests were performed at speeds of 1 to $9 \mathrm{~m} / \mathrm{s}$. The results corresponding to the trim, drag, and rise up were obtained from three different points of the vessel. Using Eq. (2), the trim could be calculated as follows:

$$
\tau=\tan ^{-1}\left(\frac{H_{2}-H_{1}}{L_{2-1}}\right),
$$

where $H_{1}$ is the height at section $1, H_{2}$ is the height at section 2 and $L_{2-1}$ is the longitudinal distance between the two points. The position of the potentiometers is shown in Figure 5. The potentiometer of section 1, was located at a distance of $145 \mathrm{~mm}$ from the stern and the potentiometer of section 10, was located at a distance of $2215 \mathrm{~mm}$ from the stern. The value of $L_{2-1}$ was $2070 \mathrm{~mm}$. The location at which the drag force was measured (load cell), was the place of the intersection of the shaft and LCG. It should be noted that the angle between the shaft line and baseline was 6 degrees in all the tests.

The process of increasing or decreasing the parameters of trim, rise-up, and resistance depends on the vessel position in the motion regime and the Froude number. The trim of a single-step no-wedge model at speeds of 3, 5, 7 and $9 \mathrm{~m} / \mathrm{s}$ is displayed in Figure 6 . Under the motion mode near the planing of the craft, i.e. at Froude number of 1 , the vessel had the highest trim, and then the trim began to decrease (Figure 6 from A to D.)

The results of the tests are presented in this section. Accordingly, the measured trim angle, rise up, and resistance are reported. Subsequently, the comparisons of different cases are presented to achieve a better understanding of the effects of wedge and transverse step. To determine the uncertainty of measured trim and resistance, all factors that affect the measurement of these values should be considered. The factors that contribute to the uncertainty of the measurements of the model include the uncertainties associated with geometry, instrumentation, and equipment installation. According to ITTC [82], these uncertainties should be at a minimum level. As defined in the ITTC [82] guidelines, some of the acceptable values for errors could be summarized as follows:

1. The model construction error must be less than $1 \mathrm{~mm}$;

2. Failure to towing the model by dynamometer must be less than 0.02 of the model weight;

3. The speed tolerance shall be less than $\pm 2 \mathrm{~mm} / \mathrm{s}$;

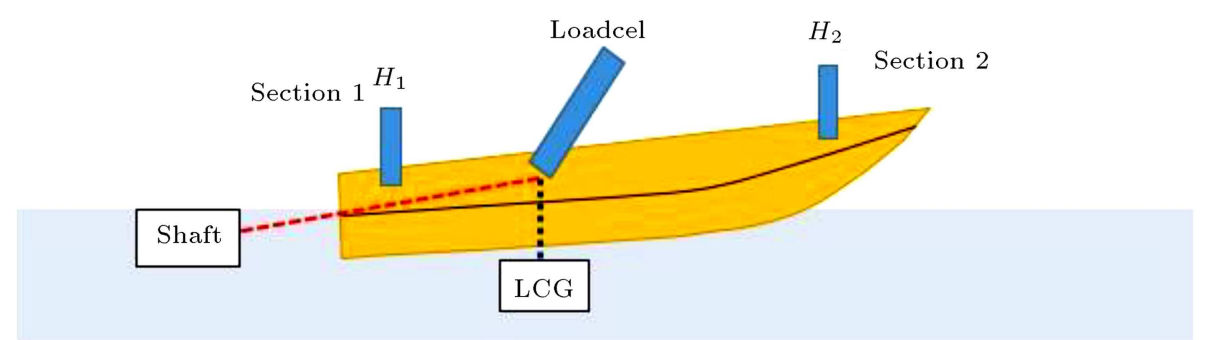

Figure 5. Load cell and potentiometer location.

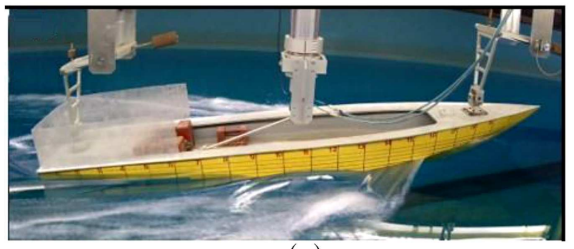

(a)

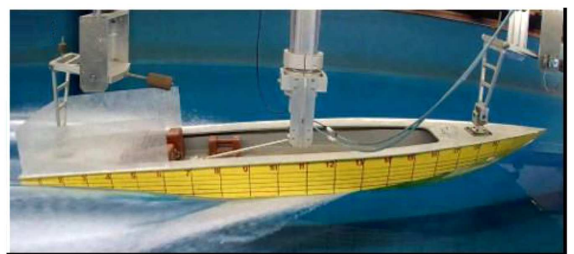

(c)

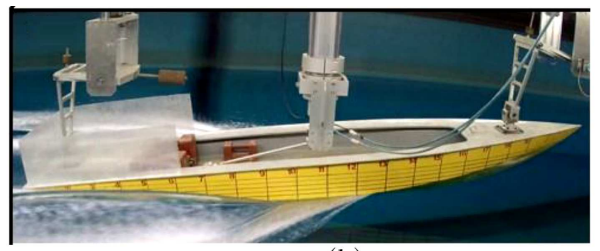

(b)

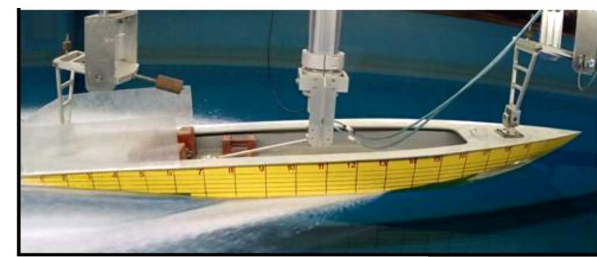

(d)

Figure 6. Considered speeds of Model B: (a) $3 \mathrm{~m} / \mathrm{s}$, (b) $5 \mathrm{~m} / \mathrm{s}$, (c) $7 \mathrm{~m} / \mathrm{s}$, and (d) $9 \mathrm{~m} / \mathrm{s}$. 
4. The ambient temperature difference shall be less than $0.1^{\circ} \mathrm{C}$;

5. Maximum acceptable load difference is $10 \mathrm{~g}$;

6. The difference between the directions of towing and the thrust shall be less than one degree;

7. The balance error shall be less than 10 grams;

8. The measurement error of the trim of fore and aft shall be less than one millimeter.

The ITTC relationships, which are used to calculate the uncertainty, are listed in Table 4.

The uncertainty calculations for each model are presented in Subsection 3.5.

\subsection{Results of Model A}

The main vessel was $13 \mathrm{~m}$ long and was designed for the ultimate speed of 40 knot. The test of the model boat at the same speed as the laboratory was needed. The speed of the model relative to the speed of the main boat is given in Table 5. The model was 1:5 scale of the main vessel and was tested up to Froude number of 1.96. For this range of the Froude number, the speeds varied from 1 to $9 \mathrm{~m} / \mathrm{s}$. At the speed of $5 \mathrm{~m} / \mathrm{s}$, the vessel was in the planing regime.

Model A (without appendage) was previously tested by Ghadimi et al. [52]. The results of the tests of Model A are presented in Table 6. For the no-step and no-wedge craft, the porpoising phenomenon was observed at the speed of $9 \mathrm{~m} / \mathrm{s}$. This implies that there was a significant distance between the center of gravity and the center of hydrodynamic force.

\subsection{Results of Model B - The no-wedge and with step model}

In the third set of experiments, a single-stepped monohull no-wedge model was investigated. The distance between the step and transom was $770 \mathrm{~mm}$ and the step had a $25 \mathrm{~mm}$ height, which was created linearly

Table 4. Definition of trim and drag uncertainty.

\begin{tabular}{|c|c|c|}
\hline No & Definition & Governing equations \\
\hline 1 & Total trim uncertainty & $\left(U_{\tau}\right)^{2}=\left(B_{\tau}\right)^{2}+\left(P_{\tau}\right)^{2}$ \\
\hline 2 & Total bias limit for trim\% of $(U \tau) 2$ & $\left(B_{\tau}\right)^{2}=\left(\theta_{V}\right)^{2}+\left(\theta_{\Delta F P} B_{\Delta F P}\right)^{2}+\left(\theta_{\Delta A P} B_{\Delta A P}\right)^{2}$ \\
\hline 3 & Trim precision limit $\%$ of $(U \tau) 2$ & $P_{\tau}=\frac{\sigma_{\tau}}{\sqrt{N}}$ \\
\hline 4 & Total bias of $\Delta F P \%$ of $\Delta F P$ & $\left(B_{\triangle F P}\right)^{2}=\left(B_{\triangle F P 1}\right)^{2}+\left(B_{\triangle F P 2}\right)^{2}$ \\
\hline 5 & Calibration bias of $\Delta F P \%$ of $(B \Delta F P) 2$ & $B_{\triangle F P 1}=\sqrt{Z_{I N C}^{2}}$ \\
\hline 6 & Potentiometer misalignment bias of $\Delta F P \%$ of $(B \Delta F P) 2$ & $B_{\Delta F P 2}=\Delta F P-\cos \left(\theta_{m}\right) \times \Delta F P$ \\
\hline 7 & Total bias of $\triangle A P \%$ of $\triangle A P$ & $\left(B_{\triangle A P}\right)^{2}=\left(B_{\triangle A P 1}\right)^{2}+\left(B_{\triangle A P 2}\right)^{2}$ \\
\hline 8 & Calibration bias of $\triangle A P \%$ of $(B \Delta A P) 2$ & $B_{\triangle A P 1}=\sqrt{Z_{I N C}^{2}}$ \\
\hline 9 & Potentiometer misalignment bias of $\triangle A P \%$ of $(B \Delta A P) 2$ & $B_{\triangle A P 2}=\Delta A P-\cos \left(\theta_{m}\right) \times \Delta A P$ \\
\hline 10 & Sensitivity coefficient for speed, V, for trim & $\theta_{V}=-4 \times g \times \frac{\Delta A P-\Delta F P}{V^{3}}$ \\
\hline 11 & Sensitivity coefficient of $\Delta F P$, for trim & $\theta_{\Delta F P}=\frac{2 g}{V^{2}}$ \\
\hline 12 & Potentiometer misalignment angle & $\theta_{M}$ \\
\hline 13 & $\Delta F P($ fore perpendicular) measured & $\Delta F P$ \\
\hline 14 & $\Delta A P$ (aft perpendicular) measured & $\triangle A P$ \\
\hline 15 & Sinkage & $\sigma$ \\
\hline 16 & Trim & $\tau$ \\
\hline 17 & Total friction in $15 \mathrm{deg}$ & $C_{T}^{15 \mathrm{deg}}=C_{T}^{T W}-\left(C_{F}^{15 \mathrm{deg}}-C_{F}^{T W}\right)(1+K)$ \\
\hline 18 & Total friction & $C_{T}^{T W}=\frac{R_{X}^{T W} \times g}{\frac{1}{2} \rho V^{2} W_{S}}$ \\
\hline 19 & Coefficient of friction & $\mathrm{CF}$ \\
\hline 20 & & $\mathrm{CR}$ \\
\hline 21 & Coefficient of the frictional resistance & $\mathrm{CT}$ \\
\hline 22 & Coefficient of the residuary resistance & $k$ \\
\hline 23 & Coefficient of the total resistance & $\operatorname{Re}$ \\
\hline 24 & Form factor; coverage factor & WS \\
\hline 25 & Reynolds number & $\mathrm{CF}$ \\
\hline 26 & Wetted surface area of ship model $\left(\mathrm{m}^{2}\right)$ & $\left(U_{C T}\right)^{2}=\left(U_{C T}^{T W}\right)^{2}+\left(K, U_{P C T}\right)^{2}$ \\
\hline 27 & Total drag uncertainty & $k, U_{P C T}=\frac{K, \sigma_{C T}}{\sqrt{N}}$ \\
\hline
\end{tabular}


on the model floor. Figure 7 shows the bottom of the mono-hull model in two schematic views. The results of the investigations conducted on the single-stepped mono-hull model are presented in Table 7 .

By changing the step position, the amount of the resistance and lift forces changed. During the tests, by decreasing the longitudinal distance between transom and step, the resistance, as well as the wetted surface area of the first body increased. Also, by increasing the

Table 5. Equivalent speed of the model relative to the main vessel.

\begin{tabular}{ccc}
\hline $\begin{array}{c}\text { Speed of model } \\
(\mathbf{m} / \mathbf{s})\end{array}$ & Froude number & $\begin{array}{c}\text { Speed of boat } \\
(\mathbf{m} / \mathbf{s})\end{array}$ \\
\hline 1 & 0.19 & 2.23 \\
3 & 0.58 & 6.70 \\
5 & 0.98 & 11.17 \\
7 & 1.37 & 15.64 \\
9 & 1.76 & 20.11 \\
\hline
\end{tabular}
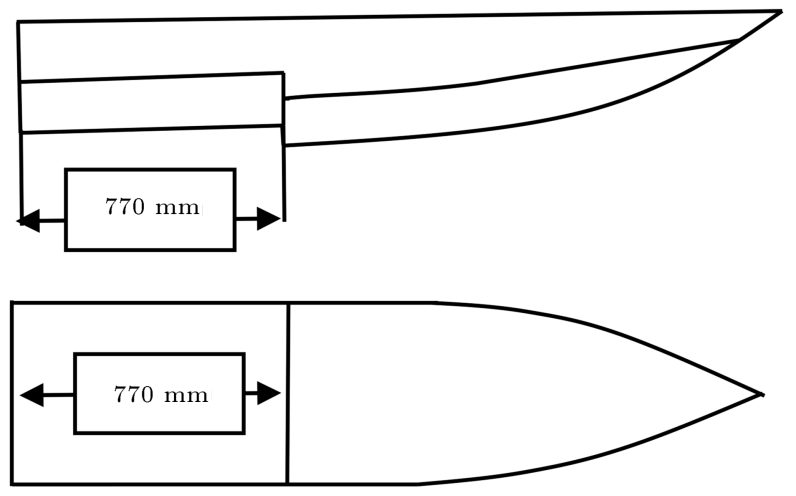

Figure 7. A sketch of the single-stepped mono-hull floor. step distance from the transom, the wetted surface area of the second body increased and the center of pressure of the first body approached the fore of the vessel, making the vessel extremely unstable. Therefore, the optimum choice was made for this vessel in accordance with the position of the center of gravity. On the other hand, due to the increase and decrease of the velocity, the flow separation became longer and shorter respectively. Therefore, the impact of the wedge is important when the step is located in the right place. Then the water reached the appropriate location in the second body. As it is clear from Table 7, the trim angle initially exhibited an increasing trend and then showed a decreasing trend. Generally, the trim angles in Model B were less than the corresponding values in Model A. Also, the resistance in Model B initially was larger than that of Model A, but over time decreased. The porpoising phenomenon in Model B was eliminated. The generation of a high-pressure area in the second body of Model B led to the increase of the longitudinal stability of this model.

\subsection{Results of Model C - The model with step and wedge}

In what follows, the results of applying a combined method in which the step and wedges appendage are combined will be discussed. In this experiment, the resistance, trim, and rise up of the vessel are measured. The test results are presented in Table 8 . The results of the tests of the CR model showed that the significant decrease of the trim led to an unfavorable increase of the wetted surface of the vessel at high speeds. From this, it can be deduced that due to the strength of the lift force at the stern, the trim was greatly reduced

Table 6. Results of Model A.

\begin{tabular}{ccccc}
\hline $\boldsymbol{V}(\mathbf{m} / \mathbf{s})$ & $\boldsymbol{F} \boldsymbol{r}_{\boldsymbol{L}}$ & \multicolumn{3}{c}{ Model A } \\
\cline { 3 - 5 } & & Rise up at CG $(\mathbf{m})$ & Trim $(\mathbf{d e g})$ & $\boldsymbol{P}(\mathbf{W})$ \\
\hline 1 & 0.21 & -0.00178 & 2.47 & 7.848 \\
3 & 0.64 & 0.00403 & 6.17 & 339 \\
5 & 1.07 & 0.05261 & 7.39 & 683 \\
7 & 1.49 & 0.08154 & 5.81 & 947 \\
9 & 1.71 & Porpoising & Porpoising & Porpoising \\
\hline
\end{tabular}

Table 7. Results of Model B (the model with a step and no wedge).

\begin{tabular}{ccccc}
\hline $\boldsymbol{V}(\mathbf{m} / \mathbf{s})$ & $\boldsymbol{F r}_{\boldsymbol{L}}$ & Rise up at CG $(\mathbf{m})$ & Trim $(\mathbf{d e g})$ & $\boldsymbol{P}(\mathbf{W})$ \\
\hline 1 & 0.21 & -0.0013 & 3.12 & 10.11 \\
3 & 0.64 & 0.00582 & 6.60 & 358.69 \\
5 & 1.07 & 0.04794 & 6.437 & 673.9 \\
7 & 1.49 & 0.07259 & 4.86 & 947 \\
9 & 1.92 & 0.080 & 3.55 & 1388.8 \\
\hline
\end{tabular}


Table 8. Results of Model C (the model with a step and a wedge).

\begin{tabular}{ccccc}
\hline $\boldsymbol{V}(\mathbf{m} / \mathbf{s})$ & $\boldsymbol{F}_{\boldsymbol{L}}$ & Rise up at CG $(\mathbf{m})$ & Trim $(\mathbf{d e g})$ & $\boldsymbol{P}(\mathbf{W})$ \\
\hline 1 & 0.21 & -0.00126 & 3.09 & 11 \\
3 & 0.64 & -0.00093 & 6.01 & 329 \\
5 & 1.07 & 0.0385 & 4.68 & 643 \\
7 & 1.49 & 0.0621 & 2.87 & 968 \\
9 & 1.92 & 0.0664 & 1.8 & 1677 \\
\hline
\end{tabular}

leading to an increase of the wetted surface which in turn caused the resistance to be increased.

\subsection{Comparison of the trim, rise up, and drag}

The diagrams of the trim, strength, and rise up of the bow, stern, and center of gravity are shown in Figures 8 to 10. A comparison of the measured trim angles for different models is shown in Figure 8. As is evident from this figure, for Model A, in which no appendages were installed, the trim had its largest value and reached a maximum value of 7.3 degrees. For the other models, the trim angle was smaller. The comparison of the trim angles of the models under consideration showed that the case with a wedge and a step had a smaller trim angle at $V>3(\mathrm{~m} / \mathrm{s})$. At speeds $V<4(\mathrm{~m} / \mathrm{s})$, the trim angle of the no appendages model (Model A) was smaller.

In Figure 8(b), the percent difference of trim angle

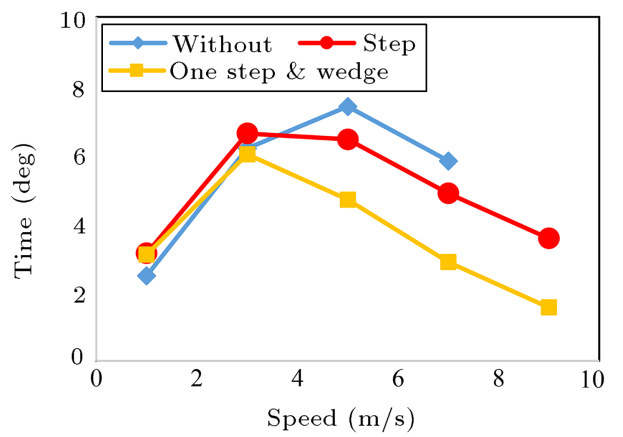

(a)

Figure 8. (a) Comparison of trim angles for different models. (b) Comparison of trim angles for different models related to Model A.

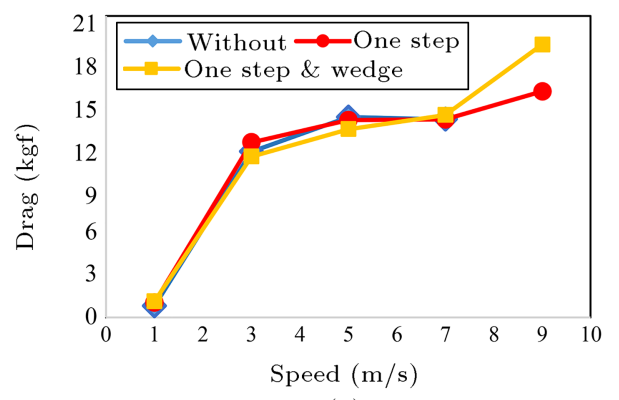

(a) between the two Models of $\mathrm{B}$ and $\mathrm{D}$ against Model A is compared based on Eq. (3). The biggest difference was observed for Model C.

$$
\text { Percentage }=\left|\frac{\operatorname{trim} A-\operatorname{trim} B(\text { or } C)}{\operatorname{trim} A}\right| \times 100 \text {. }
$$

The measured total resistances of the tested models are displayed in Figure 9. It is observed that the resistance of Model B was larger than other models at speed $V<7(\mathrm{~m} / \mathrm{s})$. The resistance of Model $\mathrm{C}$ was larger than the other models at speed $V>7(\mathrm{~m} / \mathrm{s})$. Also, the resistance of Model $\mathrm{C}$ was smaller than the other models at speed $0<V<7(\mathrm{~m} / \mathrm{s})$. Therefore, Model $\mathrm{C}$ entered the planing regime faster than other models. At speed of $9 \mathrm{~m} / \mathrm{s}$, the resistance of Model B was less than other models. Thus, it could be concluded that only at high speed, the step could reduce the resistance

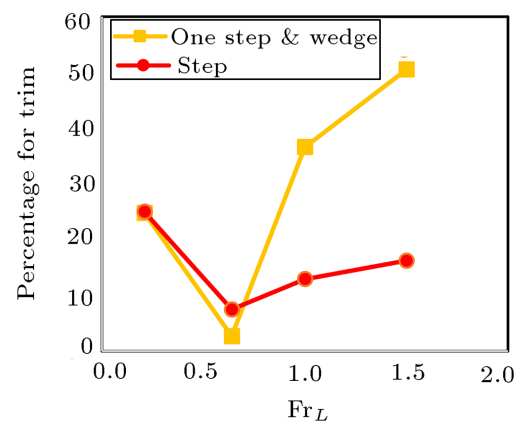

(b)

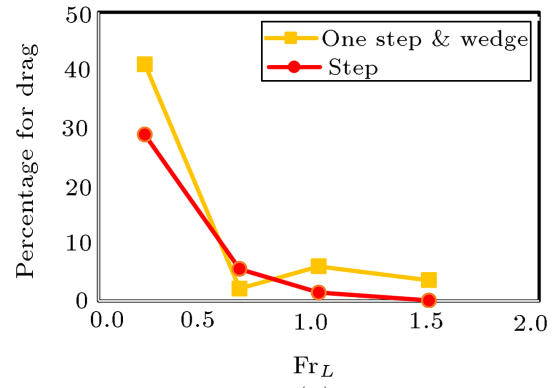

(b)

Figure 9. (a) Comparison of the resistance (drag) for different models. (b) Comparison of the resistance (drag) for different models against Model A. 


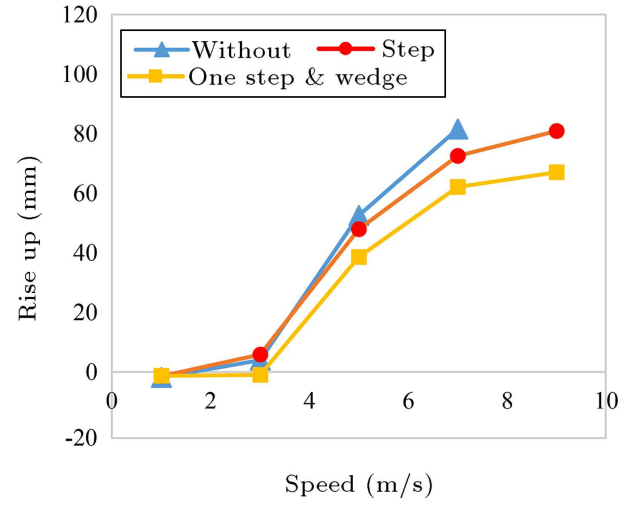

(a)

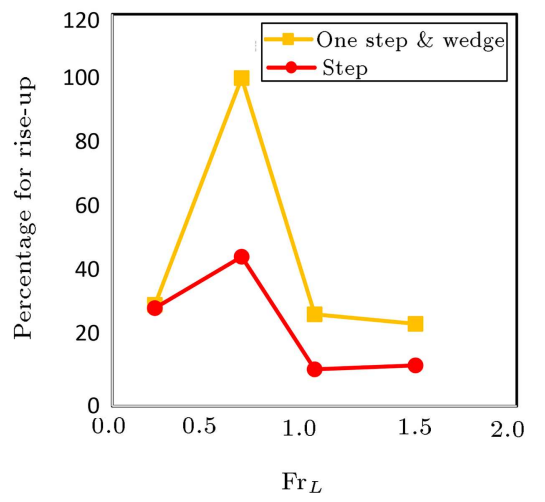

(b)

Figure 10. (a) Comparison of the center of gravity rise up for different models. (b) Comparison of the center of gravity rise up for different models against Model A.

of the vessel. Therefore, the addition of the wedge to the stepped model could lead to better performance and could improve its behavior, compared to the initial speeds of the planing regime.

In Figure 9(b), the percent difference of drag between three Models of B, C, and A is compared in accordance with Eq. (4). The highest difference was observed for Model B. This model had the lowest drag at speeds of $7 \mathrm{~m} / \mathrm{s}$.

$$
\text { Percentage }=\left|\frac{\operatorname{drag} A-\operatorname{drag} B(\text { or } C)}{\operatorname{drag} A}\right| \times 100 \text {. }
$$

Figure 10 displays the measured CG rise up for different models. As is evident in this figure, Model A had a larger $\mathrm{CG}$ rise up at $V>7 \mathrm{~m} / \mathrm{s}$ in comparison with other models. The results showed that the $\mathrm{CG}$ rise up of Model $\mathrm{C}$ was smaller than that of other models.

In Figure 10(b), the percent difference of rise up between Models of $\mathrm{B}$ and $\mathrm{C}$ are compared with Model A in accordance with Eq. (5). The highest difference was observed for Model C. This model had the lowest rise up.

$$
\text { Percentage }=\left|\frac{(\text { rise-upA })-(\text { rise-upB })(\text { or } C)}{(\text { rise-upA })}\right|
$$

$$
\times 100 \text {. }
$$

\subsection{Uncertainty}

The uncertainty calculations for each model are presented in Table 9. These calculations are based on the proposed standard of ITTC. The drag uncertainty was calculated based on the total drag coefficient. The computed values for drag and trim at different speeds are shown in Table 6. Eqs. (6) and (7) were used to calculate the uncertainty. These equations are presented in Table 6 .

$$
\left(U_{\tau}\right)^{2}=\left(B_{\tau}\right)^{2}+\left(P_{\tau}\right)^{2},
$$

Table 9. The calculated drag and trim uncertainties.

\begin{tabular}{ccccc}
\hline & \multicolumn{2}{c}{ Model B } & \multicolumn{2}{c}{ Model C } \\
\hline $\boldsymbol{V}(\%)$ & Drag (\%) & Trim (\%) & Drag (\%) & Trim (\%) \\
\hline 1 & 1.549 & 5.714 & 1.6569 & 4.048 \\
3 & 0.876 & 0.658 & 0.412 & 0.335 \\
5 & 0.428 & 0.443 & 0.4139 & 0.233 \\
7 & 0.403 & 0.767 & 0.356 & 0.669 \\
9 & 0.366 & 0.564 & 0.3454 & 0.725 \\
\hline
\end{tabular}

$$
\left(U_{C T}\right)^{2}=\left(U_{C T}^{T W}\right)^{2}+\left(K, U_{P C T}\right)^{2}
$$

The highest uncertainty was about $5 \%$ for Model B. The measurement accuracy also improved with increasing speed.

\section{Conclusions}

Simultaneous use of step and wedge on the performance of a planing hull: In single-step and wedged and stepped models, the porpoising was eliminated, due to an increase in the lift force at the stern. Through this approach, the hydrodynamic force was pulled toward the stern and the vessel became stable. In all of the models (except the no-appendage model), the trim was observed to decrease. Meanwhile, the no-appendage displayed the highest trim, since there was no lifting force at its stern location; The resistance of the singlestep model at high speeds (higher than $7 \mathrm{~m} / \mathrm{s}$ ) was less than those in other models. This is due to the fact that the bottom of the single-step model had a less wetted surface than other models. At speeds less than $7 \mathrm{~m} / \mathrm{s}$ the resistance of the combined wedge and step model was less than other models; The combined step and wedge model improved the behavior of the stepped model under the condition in which the speed 
was lower than $7 \mathrm{~m} / \mathrm{s}$. It also reached the planing regime faster than other models; As the results showed, the highest uncertainty was about $5 \%$ for the singlestep model, and the measurement accuracy improved with increasing speed.

The results of the present study can help the engineers to adopt a better mechanism for preventing the vessel instabilities or reducing the resistance. Through investigating the motions of the vessels exposed at waves and by examining how these mechanisms can affect the motions, the future study could enrich the results of the present study.

\section{Nomenclature}

\begin{tabular}{|c|c|}
\hline$B$ & $\operatorname{Beam}(\mathrm{m})$ \\
\hline$D_{B}$ & Draft at bow \\
\hline$D_{D}$ & Design draft \\
\hline$D_{T}$ & Draft at transom \\
\hline$L$ & Length $(\mathrm{m})$ \\
\hline Deg & degree \\
\hline LBP & Length Between Perpendiculars (m) \\
\hline $\mathrm{LCG}$ & Longitudinal Center of Gravity \\
\hline $\mathrm{CG}$ & Center of Gravity \\
\hline$M$ & Mass (kg) \\
\hline VCG & Vertical Center of Gravity (m) \\
\hline$X$ & Distance from transom \\
\hline$\beta$ & Deadrise angle (deg) \\
\hline$\Delta$ & Weight $(\mathrm{N})$ \\
\hline$\tau_{S}$ & Static trim angle (deg) \\
\hline$F n_{L}$ & Froude number, $F n_{L}=\sqrt{\frac{V}{g L}}$ \\
\hline$H_{1}$ & Height at section 1 (Figure 5) \\
\hline $\mathrm{H}_{2}$ & Height at section 2 (Figure 5 ) \\
\hline$C_{F}$ & Coefficient of the resistance \\
\hline$C_{R}$ & Coefficient of the residuary resistance \\
\hline$C_{T}$ & Coefficient of the total resistance \\
\hline$K$ & Form factor; coverage factor \\
\hline ITTC & International Towing Tank Conference \\
\hline$\theta_{T}$ & Potentiometer misalignment angle \\
\hline$\Delta F P$ & Fore perpendicular measured \\
\hline$\triangle A P$ & Aft perpendicular measured \\
\hline$\sigma$ & Sinkage \\
\hline$U_{T}$ & Total trim uncertainty \\
\hline$U_{C T}$ & Total drag uncertainty \\
\hline
\end{tabular}

\section{References}

1. Martin, M., Theoretical Predictions of Motions of High-Speed Planing Boats in Waves, David W. Taylor Naval Ship Research and Development Center (1976).
2. Zarnick, E., A Nonlinear Mathematical Model of Motions of a Planing Boat in Regular Waves, David W. Taylor Naval Ship Research and Development Center (1978).

3. Zarnick, E., A Nonlinear Mathematicalo Model of Motions of a Planing Boat in Irregular Waves, David W. Taylor Naval Ship Research and Development Center (1979).

4. Ghadimi, P., Dashtimanesh, A., and Faghfoore Maghrebi, Y. "Initiating a mathematical model for prediction of 6 DOF motion of planing crafts irregular waves", International Journal of Eng. Math., 2003, pp. 1-15 (2013).

5. Ghadimi, P., Tavakoli, T., and Dashtimanesh, A. "An analytical procedure for time domain simulation of roll motion of the warped planing hulls", International Journal of Mech. Eng. Part M: J. Eng. Marit. Environ., 230(4), pp. 600-615 (2015).

6. Ghadimi, P., Tavakoli, S., and Dashtimanesh, A. "Coupled heave and pitch motions of planing hulls at non-zero heel angle", Applied Ocean Research, 59, pp. 286-303 (2016).

7. Clement, E.P. and Pope, J.D., Stepless and Stepped Planing Hulls Graphs for Performance Prediction and Design, Bethesda (MD), David W. Taylor Naval Ship Research and Development Center (1961).

8. Clement, E.P. and Koelbel, J.O. "Effects of step design on the performance of planing motorboats", 4th Biennial Power Boat Symposium, The Society of Naval Architects and Marine Engineers; Miami (FL), USA (1991).

9. Clement, E.P., A Configuration for a Stepped Planing Boat Having Minimum Drag, Bethesda (MD), David W. Taylor Naval Ship Research and Development Center (2003).

10. Barry, C.D. and Duffty, V. "The stepped hull hybrid hydrofoil", Fifth International Conference on Fast Sea Transportation (1999).

11. Savitsky, D. and Morabito, R. "Surface wave contours associated with the forebody wake of stepped planing hulls", International Journal of Marine Technology, 47(1), pp. 1-16 (2009).

12. Svahn, D. "Performance prediction of hulls with transverse steps", thesis, Stockholm: Marina System Centre for Naval Architecture, KTH University (2010).

13. Garland, W.R. and Maki, K.J. "A numerical study of a two-dimensional stepped planing surface", Journal of Ship Production and Design, 28, pp. 212-239 (2012).

14. Taunton, D.J., Hudson, D.A., and Shenoi, R.A. "Characteristics of a series of high-speed hard chine planing hulls, Part 2: performance in waves", International Journal of Small Craft Technol, 153, pp. 1-22 (2011).

15. O'Reilly, C., Murphy, M., Piro, D., et al. "Modeling the flow over planing hulls with ventilated or cavitating 
steps", SNAME 13th International Conference on Fast Sea Transportation, Washington, DC, NAME-FAST2015-018 (2015). https://doi.org/10.5957/FAST-2015018

16. Loni, A., Ghadimi, P., Nowruzi, H., et al. "Developing a computer program for mathematical investigation of stepped planing hull characteristics", International Journal of Physical Research, 1(2), pp. 34-47 (2013).

17. Lee, E., Pavkov, M., and Mccue-Weil, W. "The systematic variation of step configuration and displacement for a double-step planing craft", Journal of Ship Prod Des., 30, pp. 89-97 (2014).

18. Veysi, S.T.G., Bakhtiari, M., Ghassemi, H., et al. "Toward numerical modeling of the stepped and nonstepped planing hull", Journal of the Brazilian Society of Mechanical Sciences and Engineering, 37(6), pp. 1635-1645 (2015).

19. De Marco, A., Mancini, S., Miranda, S., et al. "Experimental and numerical hydrodynamic analysis of a stepped planing hull", Applied Ocean Research, 64, pp. 135-154 (2017).

20. Najafi, A., Nowruzi, H., Salari, M., et al. "The hydrodynamic resistance of stepped planing hulls under different geometrical and physical conditions", Journals of the Maritime University of Szczecin, 58(130), pp. 24-31 (2019).

21. Najafi, A. and Nowruzi, H. "On hydrodynamic analysis of stepped planing crafts", Journal of Ocean Engineering and Science, 4, pp. 238-251 (2019).

22. Chooran, T., Shafaghat, R., and Yoosefi, R. "Numerical investigation of step depth effects on hydrodynamic performance of planing hull using dynamic mesh and two degree of freedom model", AUT Journal of Mechanical Engineering, 3(2), pp. 139-148 (2019).

23. Kazemi, H., Salari, M., Nowruzi, H., et al. "Hydrodynamics analysis of stepped planing hull under different physical and geometrical conditions", Journal of the Brazilian Society of Mechanical Sciences and Engineering, 41, pp. 360-372 (2019).

24. Ghadimi, P., Panahi, S., and Tavakoli, S. "Hydrodynamic study of a double-stepped planing craft through numerical simulations", Journal of the Brazilian Society of Mechanical Sciences and Engineering, 41(2) (2019).

25. Dashtimanesh, A., Roshan, F., Tavakoli, S., et al. "Effects of configuration on hydrodynamic performance of one and doubled-stepped planing flat plates: A numerical simulation", Journal of Engineering and Maritime Environment, 234(1), pp. 181-195 (2019).

26. Doustdar, M. and Kazemi, H. "Effects of fixed and dynamic mesh methods on simulation of stepped planing craft", Journal of Ocean Engineering and Science, 4, pp. 33-48 (2019).

27. Yang, D., Sun, Z., Jiang, Y., et al. "A study on the air cavity under a stepped planing hull", Journal of Marine Science and Engineering, MDPI, 7(12), 468 (2019). DOI: $10.3390 /$ jmse7120468
28. Cucinotta, F., Guglielmino, E., and Sfravara, F. "A critical CAE analysis of the bottom shape of a multi stepped air cavity planing hull", Applied Ocean Research, 82, pp. 130-142 (2019).

29. Ghadimi, P. and Panahi, S. "Numerical investigation of hydrodynamic forces acting on the nonstepped and double-stepped planing hulls during yawed steady motion", Journal of Engineering and Maritime Environment, 233(2), pp. 428-442 (2019). DOI: $10.1177 / 1475090217751549$

30. Nourghassemi, H., Ghassemi, H., and Taghva, H. "Numerical hydrodynamic results of the two stepped planing hull", American Journal of Mechanical Engineering, 6(3), pp. 93-97 (2018).

31. Esfandiari, A., Tavakoli, S., and Dashtimanesh, A. "Comparison between the dynamic behavior of the non-stepped and double-stepped planing hulls in rough water: A numerical study", Journal of Ship Production and Design, 6(3), pp. 93-97 (2019).

32. Najafi, A., Nowruzi, H., Karami, M., et al. "Experimental investigation of the wetted surfaces of stepped planing hulls", Ocean Engineering, 187, 106164 (2019). doi.org/10.1016/j.oceaneng.2019.106164

33. Judgea, C., Mousaviraad, M., Sternc, F., et al. "Experiments and CFD of a high-speed deep-V planing hull-Part I: Calm water", Applied Ocean Research, 96, 102060 (2020). doi.org/10.1016/j.apor.2020.102060

34. Niazmand, B.R., Vitiellob, L., Mancini, S., et al. "Calm-water performance of a boat with two swept steps at high-speeds: Laboratory measurements and mathematical modeling", International Conference on Industry 4.0 and Smart Manufacturing (ISM 2019), pp. $467-474$ (2020).

35. Afriantoni, A., Romadhoni, R., and Santoso, B. "Study on the stability of high speed craft with step hull angle variations", The 8th International and National Seminar on Fisheries and Marine Science (2020).

36. Savitsky, D. and Brown, P.W. "Procedures for hydrodynamic evaluation of planing hulls in smooth and rough water", Marine Technology, 13(4), pp. 381-400 (1976).

37. Grigoropoulos, G. and Loukakis, T. "Effect of wedges on the calm water resistance of planing hulls", In Intl. Conf. of Mar. Ind. Dev. MARIND, 96 (1996).

38. Katayama, T. "Mechanism of porpoising instabilities for high-speed planing craft", In: Proceedings of the Sixth, ISOPE Pacific/Asia Offshore Mechanics Symposium (2004).

39. Ikeda, Y. and Katayama, T. "Porpoising oscillations of very-high-speed marine craft", Philosophical Transactions of the Royal Society of London A: Mathematical, Physical and Engineering Sciences, 358(1771), pp. 1905-1915 (2000).

40. Morabito, M.G. "Investigation of dynamic instabilities in high-speed, shallow-draft boats", Transactions - 
Society of Naval Architects and Marine Engineers, 124, pp. 296-311 (2016).

41. Millard, A. "Effect of wedges on the performance characteristics of two planing hulls", Journal of Ship Research, 20(4), pp. 224-232 (1987).

42. Steen, S., Alterskjar, S.A., Velgaard, A., et al. "Performance of a planing craft with mid-mounted interceptor", In 10th International Conference on Fast Sea Transportation, Athens, Greece (2009).

43. Mansoori, M. and Fernandes, A.C. "Hydrodynamic design of the interceptor on a $2 \mathrm{D}$ flat plate by CFD and experiments", Journal of Hydrodynamics, 27(6), pp. 919-933 (2015). DOI: http:// dx. doi. org/ 10. 1016/S1001-6058(15)60558-8

44. Mansoori, M. and Fernandes, A.C. "The interceptor hydrodynamic analysis for controlling the porpoising instability in high speed crafts", Applied Ocean Research, 57, pp. 40-51 (2016).

45. Tsai, J.F., Hwang, J.L., Chau, S.W., et al. "Study of hydrofoil assistance arrangement for catamaran with stern flap and interceptor", In Proceedings of the 6th International Conference on FAST Sea Transportation, Southampton, UK, Sep. (2001).

46. Tsai, F. and Hwang, J.L. "Study on the compound effects of interceptor with stern flap for two fast mono hulls", In Proceedings of the International Conference on OCEANS '04. MTTS/IEEE TECHNO-OCEAN '04 (2005).

47. Karimi, M.H., Seif, M.S., and Abbaspoor, M. "An experimental study of interceptor's effectiveness on hydrodynamic performance of high-speed planing crafts", Polish Maritime Research, 20, pp. 21-29 (2013).

48. Ghadimi, P., Loni, A., Nowruzi, H., et al. "Paramteric study of the effects of trim tabs on running trim and resistance of planing hulls", Advances in Shipping and Ocean Engineering, 3(1), pp. 1-12 (2014).

49. Pourdel, H., Hassanzadeh Afrouzi, H., Akbari, O.A., et al. "Numerical investigation of turbulent flow and heat transfer in flat tube", Journal of Thermal Analysis and Calorimetry, 135, pp. 3471-3483 (2019).

50. Akbari, O.A., Toghraie, D., and Karimipour, A. "Numerical simulation of heat transfer and turbulent flow of water nanofluids copper oxide in rectangular microchannel with semi-attached rib", Advances in Mechanical Engineering, 8(4), pp. 1-25 (2016).

51. Hassanzadeh, H., Ahmadian, M., and Toghraie, D. "Statistical analysis of pulsating non-Newtonian flow in a corrugated channel using Lattice-Boltzmann method", Physica A: Statistical Mechanics and Its Applications, 29(3), pp. 915-934 (2019).

52. Ghadimi, P., Sajedi, S.M., and Tavakoli, S. "Experimental study of the wedge effects on the performance of a hard-chine planing craft in calm water", International Journal Science \& Technology, 26(3), pp. 13161334 (2019).

53. Karafiath, G. and Fisher, S. "The effect of stern wedges on ship powering performance", Naval Engineers Journal, 99(3), pp. 27-38 (1987).
54. Wang, C.T. "Wedge effect on planing hulls", Journal of Hydronautics, 14(4), pp. 122-124 (1980).

55. Jang, S.H., Lee, H.J., Joo, Y.R., et al. "Some practical design aspects of appendages for passenger vessels", International Journal of Naval Architecture and Ocean Engineering, 1, pp. 50-56 (2009).

56. Ghadimi, P., Loni, A., Nowruzi, H., et al. "Parametric study of the effects of trim tabs on running trim and resistance of planing hulls", Advances in Shipping and Ocean Engineering, 3(1), pp. 1-12 (2014).

57. Savitsky, D. "Hydrodynamic design of planing hulls", Marine Technology, 1(1), pp. 71-95 (1964).

58. Ikeda, Y., Yokmi, K., Hamaski, J., et al. "Simulation of running attitudes and resistance of a high-speed craft using a database of hydrodynamic forces obtained by fully captive model experiments", In 2nd International Conference on Fast Sea Transportation, Athens, Greece (1993).

59. Ghadimi, P., Tavakoli, S., Feizi Chakab, M.A., et al. "Introducing a particular mathematical model for predicting the resistance and performance of prismatic planing hulls in calm water by means of total pressure distribution", Journal of Naval Architecture and Marine Engineering, 12(2), pp. 73-94 (2015).

60. Martin, M. "Theoretical determination of porpoising instability of high-speed planing boat", David Taylor Naval Ship Research and Development Center, Report No. 76-0068 (1976).

61. Xu, L. and Troesch, A.W. "A study on hydrodynamic of asymmetric planing surfaces", In Proceedings of the 5th International Conference on Fast Sea Transportation (FAST 99), Seattle, Washington, USA (1999).

62. Ghadimi, P., Tavakoli, S., Dashtimanesh, A., et al. "Steady performance prediction of a heeled planing boat in calm water using asymmetric 2D+T model", Proceedings of the Institution of Mechanical Engineers, Part M: Journal of Engineering for the Maritime Environment (2016a).

63. Ghadimi, P., Tavakoli, S., Dashtimanesh, A., et al. "Developing a computer program for detailed study of planing hull's spray based on Morabito's approach", Journal of Marine Science and Application, 13(4), pp. 402-415 (2014).

64. Mancini, S., Pensa, C., Vittelo, L., et al. "The Failed Project of the "Heavy" MAS", Nautical and Maritime Culture, from the Past to the Future International, Conference on Nautical and Maritime Culture, pp. 159-169 (2019).

65. Jokar, H., Zeinali, H., and Tamaddondard, H. "Planing craft control using pneumatically driven trim tab", Journal of Mathematics and Computers in Simulation, 178, pp. 439-463 (Dec. 2020).

66. Song, K., Guo, C., Wang, C., et al. "Numerical analysis of the effects of stern flaps on ship resistance and propulsion performance", Journal of Ocean Engineering, 193, 106621 (2019). doi.org/10.1016/j.oceaneng.2019.106621 
67. Wang, X., Liu, L., Zhang, Z., et al. "Numerical study of the stern flap effect on catamaran' seakeeping characteristic in regular head waves", Journal of Ocean Engineering, 206, 107172 (2020). doi.org/10.1016/j.oceaneng.2020.107172

68. Hou, H., Krajewski, M., Ilter, K., et al. "An experimental investigation of the impact of retrofitting an underwater stern foil on the resistance and motion", Journal of Ocean Engineering, 205, 107290 (2020). doi.org/10.1016/j.oceaneng.2020.107290

69. Deng, R., Chen, S., Wu, T., et al. "Investigation on the influence induced by interceptor on the viscous flow field of deep-Vee vessel" Journal of Ocean Engineering, 196, 106735 (2020). doi.org/10.1016/j.oceaneng.2019.106735

70. Zou, J., Lu, S., Jiang, Y., et al. "Experimental and numerical research on the influence of stern flap mounting angle on double-stepped planing hull hydrodynamic performance", Journal of Marine Science and Engineering, 7(346), pp. 1-25 (2019).

71. Ghadimi, P., Sajedi, S.M., and Tavakoli, S. "Experimental study of the wedge effects on the performance of a hard-chine planing craft in calm water", International Journal Science \& Technology, 26(3), pp. 13161334 (2019).

72. Karimi, M., Seif, M., and Abbaspoor, M. "An experimental study of interceptor's effectiveness on hydrodynamic performance of high-speed planing crafts", Polish Maritime Research, 20, pp. 21-29 (2013).

73. Gassman, W., Kartinen, S., An Investigation into the Effects of the Step Location and the Longitudinal Center of Gravity Location on the Performance of Stepped Planing Hulls, Webb Institute, Glen Cove, NY (1994).

74. Becker, C., Loreto, A., and Shell, J., A Systematic Study of Stepped Planing Hulls, Glen Cove, NY: Webb Institute (2008).

75. Taunton, D.J., Hudson, D.A., and Shenoi, R.A. "Characteristics of a series of high speed hard chine planing hills- Part 1: Performance in calm water", International Journal of Small Craft Technology, 152(2), pp. 55-74 (2010).

76. Suwasono, B., Akbar, H.M.A., Sahir, A., et al. "Outrigger RC boat model hull development as a high speedcraft based on resistance and lift force", Procedia Engineering, 194, pp. 197-202 (2017).

77. Cucinotta, F., Guglielmino, E., and Sfravara, F. "An experimental comparison between different artificial air cavity designs for a planing hull (PART I)", Ocean Engineering, 140, pp. 233-243 (2017).

78. Kim, D.J., Kim, S.Y., You, Y.J., et al. "Design of highspeed planing hulls for the improvement of resistance and seakeeping performance", International Journal of Naval Architecture, 5, pp. 161-177 (2013).

79. Ma, W.J., Sun, H.B., Zou, J., et al. "Test studies of the resistance and seakeeping performance of trimaran planing hull", Polish Maritime Research, 22, pp. 22-27 (2015).

80. Jiang, Y., Zou, J., Hu, A., et al. "Analysis of tunnel hydrodynamic characteristics for planing trimaran by model test and numerical simulations", Ocean Engineering, 113, pp. 101-110 (2016).

81. Seo, J., Choi, H.K., Jeong, U.C., et al. "Model tests on resistance and seakeeping performance of wavepiercing high-speed vessel with spray rails", International Journal of Naval Architecture and Ocean Engineering, 8(5), pp. 442-455 (2016).

82. ITTC-Recommended Procedures and Guidelines, 24th ITTC 7.5-02 07-02.1 (2013).

\section{Biographies}

Sayyed Mahdi Sajedi received her BS and MS degrees in Naval Architecture from Malek Ashtar University of Technology in years 2008 and 2013, respectively. $\mathrm{He}$ was then admitted to the $\mathrm{PhD}$ program in the Department of Maritime Engineering in the year 2016 and is currently working on his dissertation. His main research interests include hydrodynamics planing hulls, and he has authored six articles on this topic.

Parviz Ghadimi received his $\mathrm{PhD}$ in Mechanical Engineering in 1994 from Duke University, USA. He served one year as a Research Assistant Professor in Mechanical Engineering Department and six years as a Visiting Assistant Professor in Mathematics Department at Duke. He then joined the Department of Marine Technology at Amirkabir University of Technology, Iran, in Fall 2005. He is currently a Full Professor of Hydromechanics at that department. His main research interests include hydrodynamics, hydroacoustics, thermo-hydrodynamics, and CFD, and he has authored over two hundred scientific papers in these fields.

Mohammad Sheikholeslami is a graduate student of hydrodynamics at the Department of Maritime Engineering at Amirkabir University of Technology (AUT), Tehran, Iran. He received his BSc degree in Naval Architecture from the same department in 2018. His areas of research interest include planing hulls, hydrofoil applications, and flow pattern modeling. He is the co-author of four scientific papers.

Mohammad Aref Ghassemi received his BS degree in Marine Engineering from Persian Gulf University in 2017. He then received an MS degree in Ship Hydrodynamics from the Department of Maritime Engineering at the Amirkabir University of Technology in 2019. His main research areas include planing hulls and ship propellers and he has coauthored three scientific papers. 